\title{
Detection of Periodontal Markers in Chronic Periodontitis
}

\author{
Åsa Leonhardt ${ }^{1, *}$, Anette Carlén ${ }^{2}$, Lisbeth Bengtsson ${ }^{2}$ and Gunnar Dahlén ${ }^{2}$ \\ ${ }^{1}$ Student Clinic, Public Dental Health Service, Västra Götaland Region, Sweden \\ ${ }^{2}$ Department of Oral Microbiology, Institute of Odontology, Sahlgrenska Academy at University of Gothenburg, \\ Gothenburg, Sweden
}

\begin{abstract}
The aim was to compare the detection frequency of periodontopathogens by using the Pado Test 4.5 and checkerboard DNA-DNA hybridization technique in chronic periodontitis patients.

Thirty patients with chronic periodontitis were tested cross-sectionally with DNA/RNA oligogenomic probe method (IAI Pado Test 4.5) and DNA/DNA whole genomic probe (checkerboard) method. Samples were taken by two paper points at the deepest site in each of the four quadrants and pooled into one sample for each of the two methods. The samples were sent to the two laboratories (IAI, Zuchwil, Switzerland, and Oral Microbiology Laboratory, University of Gothenburg, Sweden) and were analyzed in a routine setting for the presence and amount of Aggregatibacter actinomycetemcomitans, Porphyromonas gingivalis, Tannerella forsythia and Treponema denticola.

While Pado Test 4.5 detected the four periodontal pathogens in 11 (36.7\%) of the patients, the checkerboard method showed presence in all patients $(100 \%)$ using the lower score (Score 1 corresponding to $10^{4}$ bacterial cells) and 16 $(53.3 \%)$ using a higher treshold (score 3 corresponding to between $>10^{5}$ and $10^{6}$ cells).

The results of the present study showed low agreement for a positive microbiological outcome using the two diagnostic methods. It was also concluded that microbiological analysis in practice should include a larger number of bacterial species to better serve as markers for a diseased associated flora in chronic periodontitis cases.
\end{abstract}

Keywords: Chronic periodontitis, Microbiological diagnostic methods, PadoTest 4.5, Checkerboard DNA-DNA hybridization, Aggregatibacter actinomycetemcomitans, Porphyromonas gingivalis, Tannerella forsythia, Treponema denticola.

\section{INTRODUCTION}

Diagnosis of periodontal disease and evaluation of periodontal therapy are usually based on clinical parameters including attachment loss (AL), probing pocket depth (PPD) and bleeding on probing (BOP). While they are decisive for the diagnosis and the initial treatment they need to be supported in non-responders after the initial therapy for decision for further therapy [1]. A microbiological diagnosis has thus been suggested to complement the clinical diagnosis and to be used for guidance for more aggressive treatment such as surgery and antibiotics [2-6]. There is confusion both scientifically and in practice on the criteria for sampling, when, where and how to sample, what microorganisms should be tested, which methods should be used and how to interpret the results [7].

Several methods have been used for microbiological testing in periodontitis [8]. Most methods are focused on the presence of Aggregatibacter actinomycetemcomitans and the three "red complex" bacteria Porphyromonas gingivalis, Tannerella forsythus and Treponema denticola. Many techniques have not been fully accepted due to low sensitivity or specificity and they are sometimes slow, laborious and expensive. In recent years molecular biology

\footnotetext{
*Address correspondence to this author at the Public Dental Health Service Student clinic Institute of Odontology Box 716340233 Gothenburg Sweden; Tel: +46 31786 3220; Fax: +46 317863100 ;

E-mail: asa.leonhardt@vgregion.se
}

methods such as whole genomic probes or oligogenomic based probes (Checkerboard DNA-DNA hybridization technology) and quantitative or qualitative PCR based methods have been introduced [9-17]. Despite some of the comparisons made we still do not know which method is the most appropriate in a given case. This could partly be explained by the lack of a gold standard. Culture techniques were used in the past as a gold standard but is less usable dealing with "difficult to culture" or "unculturable" bacteria. Consequently, comparisons between such methods based on different principles needs to be performed in clinical settings that best can answer the question on the presence and proportions of the bacterial species (markers) and serve as a guidance for the treatment strategy.

Several methods for microbiological testing have become commercialized. One such test is the IAI PadoTest 4.5 based on oligonucleotid probes against the 16S rRNA gene of 4 target species claimed to be indicators species for disease activity $[18,19]$. Although the PadoTest 4.5 has been used in several investigations [20-22] it has not been evaluated with other methods used in clinical practice, except for one study [23] where the PadoTest 4.5 (IAI, Zuchvil, Switzerland) was compared with a similar DNA/RNA based method (MERI, Gaba GmbH, Lörrach, Germany). In the present study, the PadoTest 4.5 method was compared with the checkerboard DNA-DNA hybridization method against four bacterial marker species in chronic periodontitis patients. 


\section{MATERIALS AND METHODS}

\section{Subjects}

30 adults, 21 females and 9 males, with generalized chronic periodontitis (bone loss $>2 / 3$ of the root length at several teeth) were recruited for the study. They were referred to a specialist clinic for treatment of chronic periodontitis. The clinic regularly uses microbiological samples in the treatment planning and risk evaluation of cases with advanced periodontitis. The patients were all informed about the sampling and none refused to participate.

\section{Clinical Registration and Radiographs}

Full mouth recordings were taken at six sites per tooth except for third molars. Plaque (PII) and Bleeding on probing $(\mathrm{BoP})$ was scored as being absent or present $(0$ or 1$)$ and $\%$ sites with plaque and $\mathrm{BoP}$ were calculated. Probing pocket depths (PPD) were measured and recorded in $\mathrm{mm}$ using a periodontal probe (Hu Friedy, Chicago, IL, USA) and were rounded to the nearest upper millimeter. Radiographs were taken to confirm the extent of bone loss.

\section{Microbiological Sampling}

In each of 4 quadrants, one site with a remaining pocket depth of $\geq 4 \mathrm{~mm}$ was selected for microbiological sampling with the paper point technique. Two paper points (one point delivered from the PadoTest 4.5 kit and one sterilized medium size paperpoint (size 45, Roeko, Coltène/Whaledent, Langenau, Germany) were concomitantly inserted in the periodontal pocket and kept in place for 10 secs. The $4 \mathrm{~Pa}-$ doTest 4.5 points (green marked at the top) taken from the same patients were pooled for the PadoTest 4.5. The samples were sent for analysis to the Institute fur Angewandte Immunologie (IAI, Zuchwil, Switzerland). The other 4 points from the same patients were pooled into $150 \mu \mathrm{l}$ TE buffer for analysis with the checkerboard methodology and sent to the laboratory of Oral Microbiology, Institute of Odontology, Sahlgrenska Academy at University of Gothenburg, Sweden. The samples were handled in the routine outline of the two laboratories and they did not know they participated in a comparative study.

\section{IAI PadoTest 4.5 (a DNA/RNA Probe Method)}

The procedures are based on oligonucleotid probe technology according to standard procedures [23]. According to their protocol the samples were hybridized for the 16S rRNA gene of A. actinomycetemcomitans, P. gingivalis, T. forsythia, T. denticola and to an universal bacterial probe (IAI and MicroProbe Corporation, Bothwell, WA, USA).

\section{Checkerboard Technique (a DNA/DNA Probe Method)}

The presence and level of the four species A. actinomycetemcomitans, $P$. gingivalis, $T$. forsythia, $T$. denticola were determined with the aid of the checkerboard DNA-DNA hybridization methodology according to Dahlén and Leonhardt, [24]. In the routine setting in the laboratory the checkerboard panel contains additional 8 species, Campylobacter rectus, Filifactor alocis, Fusobacterium nucleatum, Parvimonas micra, Porphyromonas endodontalis, Prevotella intermedia, Prevotella nigrescens and Prevotella tannerae. In brief, whole genomic DNA probes were prepared from the panel of bacterial species using a digoxygenin labelling kit (Roche, Mannheim, Germany). The plaque samples were denaturated with $0.5 \mathrm{M} \mathrm{NaOH}$, freezed and thawed 5 times and finally the bacterial cells were mechanically disrupted of by vortexing with glass beads. The samples were then boiled for $5 \mathrm{~min}$, neutralized with ammonium acetate, transferred onto nylon membranes (Minislot device, Immunetics, Cambridge, MA) and fixed by UV-light. After $2 \mathrm{~h}$ of prehybridisation at $42^{\circ} \mathrm{C}$, the DNA probes were allowed to hybridize over night in lanes vertically to the plaque and saliva samples using a Miniblotter device (Immunetics) at $42^{\circ} \mathrm{C}$. After a series of stringency washes at $70^{\circ} \mathrm{C}$, hybrids were detected using phosphatase-conjugated anti-digoxygenin antibodies and the signals were visualised with a chemiluminescent substrate (CDP-Star, Roche). Evaluation of the number of bacteria in the samples was performed by comparing the obtained signals with the ones generated by pooled standard samples containing $10^{6}$ and $10^{5}$ cells of each species. The results were transferred to a scoring system $(0-$ 5 ), where 0 indicated no signals, score 1 visible signals corresponding to $<10^{5}$ and score 3 signals corresponding between $10^{5}-10^{6}$ cells.

\section{Control Samples}

A series of control samples were prepared from plaque sampled with curette from 5 periodontally healthy students, who had abstained from tooth brushing for one day. The plaque from each student was suspended into $100 \mu \mathrm{l}$ TEbuffer and $10^{6}$ cells of each target bacteria were then added to make a positive control sample with a mixed microbial population. From these suspensions paper point samples were taken, one for PadoTest 4.5 and one for checkerboard analysis mimicking true samples taken directly from periodontal pockets. The control samples were also blinded for the two laboratories.

\section{Statistical Calculation}

Agreement (\%) between the two methods was calculated (statistical package SAS 8.2) for the 4 target bacterial species and a kappa coefficient was calculated for each target bacteria using score $>1$ or score $>3$ for checkerboard results versus PadoTest 4.5.

\section{RESULTS}

\section{Clinical Recordings}

The 30 patients had a mean age 57 ( $\mathrm{SD} \pm 11$, range 39 81). They had $23.7 \pm 4.2$ remaining teeth (range 16-28), $75.5 \pm 12.0 \%$ sites $\geq 4 \mathrm{~mm}$ and $5.5 \pm 9.2 \%$ sites with $\mathrm{PPD}$ $\geq 7 \mathrm{~mm}$. Full mouth PII, BoP, and PPD recordings are shown in Table 1. The mean probing pocket depth of sampling sites were $5.54 \pm 0.71 \mathrm{~mm}$ and mean BoP at sampling sites $77.5 \pm 17.7 \%$. All sampling sites were clinically defined as diseased.

\section{Bacterial Marker Frequency}

The 3 red complex bacteria ( $P$. gingivalis, T.denticola, $T$. forsythia) were frequently found with the checkerboard method at the score 1 and more and considerably less at score $\geq 3$ (Table 2). The PadoTest 4.5 identified the 3 red complex bacteria in a lower frequency. A. actinomycetem- 
Table 1. Clinical Parameters Full Mouth and in Sample Sites of 30 Patients with Periodontitis Used for Comparison Between Two Microbiological Tests

\begin{tabular}{|c|c|c|}
\hline Clinical Parameters & Full Mouth Recordings & Recordings at Sample Sites \\
\hline \hline PPD (mean_SD) & $4.7+0.92$ & $5.54 \pm 0.71$ \\
\hline BoP $\%($ mean_SD) & $60.9+16.3$ & $77.5 \pm 17.7$ \\
\hline PII \% (mean+SD) & $60.6+15.7$ & $62.9 \pm 17.7$ \\
\hline
\end{tabular}

comitans was detected with the checkerboard technique in 11 of the 30 patients $(36.7 \%)$ at score 1 while in no case it was identified using the Pado test 4.5. In all, 16 patients $(53.3 \%)$ indicated a disease associated flora in the checkerboard analysis while $11(36.7 \%)$ was indicated with the PradoTest 4.5 (Table 2). Table 3 showing the extended panel of bacterial species in the checkerboard method shows that other bacterial species also were quite frequent in the samples. Thus $P$. tannerae and $F$. alocis were present in around $50 \%$ of the cases and any of the 12 bacterial markers at score 3 or more was found in $83.3 \%$.

\section{Correlation (Agreement) Between Pado test 4.5 and Checkerboard Technique}

The agreement (\%) between the two methods was seemingly high (agreement $>50 \%$ ) for 3 of the marker bacteria (except T. denticola with an agreement of 19\%), when score 1 was used as cut off point for the checkerboard method (Table 4). When score $\geq 3$ was used, the agreement was even higher, explained by the increase of negative samples with both methods. In 17 (57\%) samples the checkerboard was positive and the Pado test was negative and 4 of the samples were positive for more than 1 species (Table 4). The kappa statistics showed that this agreement was not at an acceptable level. The agreement for A. actinomycetemcomitans was $100 \%$ due to all samples were negative with both methods.

\section{Control Samples}

The five control samples in which $10^{6}$ cells of the 4 target species were added to plaque samples from periodontally healthy students showed no agreement between the PadoTest 4.5 (Table 5). The PadoTest 4.5 identified the added $P$. gingivalis only and as present in low number (score 1) in one sample. The checkerboard showed score 5 for all 4 target species in all 5 samples.

\section{DISCUSSION}

The agreement for a positive outcome of 4 bacterial periodontal markers between the PadoTest 4.5 and the checkerboard DNA-DNA hybridization method was found to be low. When the score 3 (corresponding to $10^{6}$ cells) was used as cut off level for the checkerboard this method disclosed more positive (53.3\%) samples than the PadoTest 4.5 $(36.7 \%)$ (Table 2$)$. For each of the individual markers (target bacteria) the discrepancy between the two methods was even more pronounced. Only in two cases the two methods concomitantly disclosed the same bacteria (T.denticola). PadoTest 4.5 showed a negative outcome in 17 samples (57\%) for which the checkerboard showed a positive outcome using the higher cut off level. This indicates a lower detection sensitivity of the PadoTest 4.5. On the other hand in 2 samples a higher score was found with PadoTest 4.5 than the checkerboard indicating methodological shortcomings may prevail with both methods.

For this study, patients were selected with moderate to advanced chronic periodontitis and with an expected high frequency of marker bacteria. The detection frequencies found indicated a low sensitivity of the PadoTest 4.5 method compared to the checkerboard method. The PadoTest 4.5 thus seems to underestimate the number of positive sites/individuals suggested by a high number of false negatives. From the control experiment where cells of the target bacteria were added to plaque samples taken from students it was obvious that the PadoTest 4.5 did not detect the marker bacteria to the same extent as the checkerboard method. It is possible that the difference in transport time and the time lapse of several days before analysis may explain some of the discrepancy between the methods. Presence of bacterial DNAses in the sample may degrade bacterial DNA leading to a lower level of target DNA. The checkerboard sample was processed immediately. PadoTest 4.5 has been compared with a similar DNA/RNA oligoprobe method MERDI [23] and showed a good agreement for three of the species $P$. gingivalis, $T$. forsythia and $T$. denticola. It was claimed [23] that the sensitivity of DNA/RNA oligonucleotide probes has a slightly lower sensitivity $\left(10^{4}-10^{5}\right.$ cells) compared to whole genomic DNA/DNA hybridization methods such as the used checkerboard technique. The checkerboard has been calculated to have a detection level of $10^{4}$ which can explain the higher detection rate of the marker bacteria [25]. On the other hand, the specificity in the PadoTest 4.5 is supposed to be higher due to the risk for cross-hybridizations between related species using the checkerboard method and whole genomic probes [10]. Cross-reactions lower the specificity and increase a risk for a higher frequency of false positives [25] when using the lower threshold level (Score 1) for detection. Consequently, using Score 3 as a more reliable level for a biological cut off gives a higher specificity. The number of diseased patients, which should be treated as indicated microbiologically was 16 (53.3\%) using the checkerboard method. On the other hand, the remaining 14 patients are maybe false negatives at this cut off if the 4 marker bacteria are used. At the lower score (score 1) all 30 patients indicated a diseased flora. If the entire checkerboard panel of 12 bacteria is used, 25 patients were positives at score 3 . This shows the necessity to expand the number of marker bacteria associated with disease. Clinically all 30 patients were untreated and defined as periodontally diseased. Consequently, chronic periodontitis should be regarded as a polymicrobial infection with a rather limited specificity if the red complex and $A$. actinomycetemcomitans are used as markers. 
Table 2. Comparison Checkerboard and PadoTest 4.5

\begin{tabular}{|c|c|c|c|}
\hline Bacterial Markers & $\begin{array}{c}\text { Checkerboard } \\
\text { Score }>\mathbf{1} \\
\text { No of samples (\%) }\end{array}$ & $\begin{array}{c}\text { Checkerboard } \\
\text { Score }>\mathbf{3} \\
\text { No of samples (\%) }\end{array}$ & $\begin{array}{c}\text { PadoTest 4.5 } \\
\text { Presence of Marker } \\
\text { No of samples (\%) }\end{array}$ \\
\hline \hline A. actinomycetemcomitans & $10(33.3)$ & $0(0)$ & $0(0)$ \\
\hline P. gingivalis & $16(53.3)$ & $5(16.5)$ & $9(30.0)$ \\
\hline T. denticola & $29(96.7)$ & $11(36.7)$ & $3(16.7)$ \\
\hline T. forsythia & $18(60.0)$ & $10(33.3)$ & $3(10.0)$ \\
\hline Any of the 4 markers & $30(100)$ & $16(53.3)$ & $11(36.7)$ \\
\hline Total bacterial load (TBL) & nd & nd & $34.1+14.8^{*}$ \\
\hline
\end{tabular}

nd $=$ not determined

*TBL according to PadoTest protocol (Unknown sort)

Table 3. Presence (Score Frequency) in Samples Analysed with the Checkerboard Method

\begin{tabular}{|c|c|c|}
\hline Bacterial Markers & $\begin{array}{c}\text { Checkerboard } \\
\text { Score }>\mathbf{1} \\
\text { No of Samples (\%) }\end{array}$ & $\begin{array}{c}\text { Checkerboard } \\
\text { Score }>\mathbf{3} \\
\text { No of Samples (\%) }\end{array}$ \\
\hline \hline P. intermedia & $14(46.7)$ & $14(26.7)$ \\
\hline P. nigrescens & $16(56.7)$ & $2(6.7)$ \\
\hline F. nucleatum & $25(83.3)$ & $10(33.3)$ \\
\hline P. micra & $24(80.0)$ & $1(3.3)$ \\
\hline C. rectus & $18(60.0)$ & $9(30.0)$ \\
\hline E. corrodens & $30(100)$ & $15(50.0)$ \\
\hline P. tannerae & $29(96.7)$ & $16(53.3)$ \\
\hline F. alocis & $17(56.7)$ & $8(26.7)$ \\
\hline P. endodontalis & $30(100)$ & $25(83.3)$ \\
\hline 1-12 of the markers & & \\
\hline
\end{tabular}

Table 4. Agreement of Bacterial Markers with the Use of Prado Test 4.5 Versus Checkerboard in Pooled Samples (4 Sites) from 30 Patients with Chronic Periodontitis

\begin{tabular}{|c|c|c|c|c|c|c|}
\hline $\begin{array}{c}\text { Bacterial species } \\
\text { Score } \geq 1 \text { Checkerboard }\end{array}$ & $\begin{array}{c}\text { PadoTest + } \\
\text { Checkerboard + }\end{array}$ & $\begin{array}{c}\text { PadoTest + } \\
\text { Checkerboard - }\end{array}$ & $\begin{array}{c}\text { PadoTest - } \\
\text { Checkerboard + }\end{array}$ & $\begin{array}{c}\text { PadoTest - } \\
\text { Checkerboard - }\end{array}$ & Aggreement \% & $\begin{array}{c}\text { Kappa } \\
\text { Coefficient }\end{array}$ \\
\hline A. actinomycetemcomitans & 0 & 0 & 11 & 19 & 63.3 & $<0.0001$ \\
\hline P. gingivalis & 3 & 0 & 13 & 14 & 56.7 & 0.17 \\
\hline T. denticola & 5 & 0 & 24 & 1 & 20.0 & 0.01 \\
\hline \multicolumn{7}{|l|}{ Score $\geq 3$ checkerboard } \\
\hline A. actinomycetemcomitans & 0 & 0 & 0 & 30 & 100 & n.d \\
\hline$P$. gingivalis & 0 & 0 & 5 & 25 & 83.3 & $<0.0001$ \\
\hline T. denticola & 2 & 0 & 9 & 19 & 70.0 & 0.20 \\
\hline
\end{tabular}

* Kappa statistics calculated for checkerboard score 1 and higher 
Table 5. Number of Positive Control Samples with Target Cells Added to Plaque Samples and Analyzed with PadoTest 4.5 and Checkerboard (Score $\geq 3)$

\begin{tabular}{|c|c|c|}
\hline Bacterial Species & PadoTest 4.5 & Checkerboard \\
\hline \hline A. actinomycetemcomitans & 0 & 5 \\
\hline P. gingivalis & 1 & 5 \\
\hline T. denticola & 0 & 5 \\
\hline T. forsythia & 0 & 0 \\
\hline No cells added & 0 & 5 \\
\hline
\end{tabular}

There is a risk for false negatives using only one test occasion. A repeated evaluation of each patient would probably ncrease the number of positives with both methods due to methodological variations in sampling, handling, and transportation and in the laboratory process. On the other hand repeated sampling and analyzing will extend the diagnostic period and become too expensive and will not be an option in the clinical practice.

No method is ideal for detecting periodontitis associated bacteria. The lack of a gold standard method makes it difficult to evaluate the best method for a reliable detection of the microflora and bacterial markers of deep periodontal pockets. That would speak for a more sensitive methodology such as a PCR based method with detection below $10^{2}$ cells. On the other hand such sensitive method may certainly increase the number positives also in non-diseased pockets and patients. Thus a higher sensitivity leads to an increased number of false positives, a misguidance of diagnosis and maybe an overtreatment of the patient. If there is a certain threshold for which the true positives are high and false positives are low is not known.

The importance of various microorganisms in periodontitis progression has changed from the specific plaque hypothesis in the 80 's over clusters and complexes to the ecological plaque hypothesis proposed by Marsh [26]. With this hypothesis as a basis for the choice of an appropriate method to disclose a diseased related microflora should include a panel of bacteria to cover the differences in the microbiological pattern from one patient to another. The checkerboard method with an extended panel would be more ideal and clinically useful [24].

Microbiological diagnosis was used in this study on untreated patients with chronic periodontitis with the purpose of disclosing many positives in order to get an appropriate comparison between the two methods. On the other hand, microbiological analysis has little to add for patients and sites that already by clinical criteria are diagnosed as diseased. Microbiological analysis would be more informative to perform as an adjunct to clinical diagnosis after treatment to evaluate whether site/patients has been sufficiently treated. Then a presence of markers at high scores would indicate a remaining disease associated flora and these sites should be retreated with the aim of changing the ecology of the periodontal pocket (pocket elimination by surgery and/or antibiotics). The Pado test 4.5 could not detect the bacteria placed in the control samples. We therefore challenge the utility of the test. A method for microbiological analysis that is cheap and convenient and that allow sampling of many sites and detecting many relevant markers but not necessarily be very sensitive should be used. The checkerboard methodology would fulfill many of these requirements.

\section{ACKNOWLEDGEMENTS}

This study was supported by the Public Dental Health Service, Västra Götaland, Sweden.

\section{REFERENCES}

[1] Brochut PF, Marin I, Baehni P, Mombelli A. Predictive value of clinical and microbiological parameters for the treatment outcome of scaling and root planning. J Clin Periodontol 2005: 32: 695-701.

[2] Levy D, Csima A, Birek P, Ellen RP, McCulloch C. Impact of microbiological consultation on clinical decision making: a clinical case-control study of clinical mangement of recurrent periodontitis. J Periodontol 1993; 64: 1029-39.

[3] Suchett-Kaye G, Morrier JJ, Barsotti O. Clinical usefulness of microbiological diagnostic tools in the management of periodontal disease. Res Microbiol 2001; 152: 631-9.

[4] Listgarten MA, Loomer PM. Microbial identification in the management of periodontal disease. Ann Periodotol 2003; 8: 182-92.

[5] Ezzo PJ, Cutler CW. Microorganisms as risk indicators for periodontal disease. Periodontology 2000 2003; 32: 24-35.

[6] Shaddox LM, Walker C. Microbial testing in periodontitis: value, limitations and future directions. J Periodontol 2000 2009; 50: 2538 .

[7] Dahlén G. Microbiological diagnostics in oral diseases. Acta Odont Scand 2006; 64: 164-8.

[8] Loomer PM. Microbiological testing in the treatment of periodontal diseases. Periodontol 2000 2004; 34: 49-56.

[9] Ashimoto A, Chen C, Bakker I, Slots J. Polymerase chain reaction detection of 8 putative periodontal pathogens in subgingival plaque of gingivitis and advanced periodontitis lesions. Oral Microbiol Immunol 1996; 11: 266-73.

[10] Wong M, DiRienzo, Lai C-H, Listgarten MA. Comparison of randomly cloned and whole genomic DNA probes for the detection of Porphyromonas gingivalis and Bacteroides forsythus. J Periodot Res 1996; 31: 27-35.

[11] Riggio MP, Macfarlane TW, Mackenzie D, Lennon A, Smith AJ, Kinane D. Comparison of polymerase chain reaction and culture methods for detection of Actinobacillus actinomycetemcomitans and Porphyromonas gingivalis in subgingival plaque samples. $\mathrm{J}$ Periodontal Res 1996; 31: 496-501.

[12] Papapanou PN, Madianos PN, Dahlén G, Sandros J. "Checkerboard" versus culture: a comparison between two methods for identification of subgingival microbiota. Eur J Oral Sci 1997; 105: 38996.

[13] Eick S, Pfister W. Comparison of microbial cultivation and commercial PCR based method for detection of periodontopathogenic species in subgingival plaque samples. J Clin Periodontol 2002; 29: 638-44.

[14] Moraes SR, Siquerira JF Jr, Colombo AP, Rocas IN, Ferreira MC, Domingues RM. Comparison of the effectiveness of bacterial culture, 16S rDNA directed polymerase chain reaction and checker- 
board DNA-DNA hybridization for detection of Fusobacterium nucleatum in endodontic infections. J Endodont 2002; 28: 86-9.

[15] Lau L, Sanz M, Herrera D, Morillo JM, Martin C, Silva A. Quantitative real-time polymerase chain reaction versus culture; a comparison between two methods for the detection and quantification of Actinobacillus actinomycetemcomitans. Porphyromonas gingivalis and Tannerella forsythensis in subgingival plaque. J Clin Periodontol 2004; 31: 1061-9.

[16] Boutaga K, van Winkelhoff AJ, Vandenbrouke-Grauls CM, Savelkoul PH. Periodontal pathogens: a quantitative comparison of anerobic culture and real-time PCR. FEMS Immunol Med Microbiol 2005; 45: 191-9.

[17] Haffajee AD, Yaskell T, Torresyap G, Teles R, Socransky SS. Comparison between polymerase chain reaction-based and checkerboard DNA hybridization techniques for microbial assessment of subgingival plaque samples. J Clin Periodontol 2009; 36: 642-9.

[18] Dix K, Watanabe SM, McArdle S, Lee DI, Randolph C, Moncla B, Schwartz DE. Species-specific oligodeoxynucleotid probes for the identification of periodontal bacteria. J Clin Microbiol 1990; 28: 319-23.

[19] Moncla BJ, Braham P, Dix S, Watanabe S, Schwartz D. Use of synthetic oligonuceotide DNA probes for identification of Bacteroides gingivalis. J Clin Microbiol 1990; 28: 324-7.
[20] Luterbacher S, Mayfield L, Brägger U, Lang NP. Diagnostic characteristics of clinical and microbiological tests for monitoring periodontal and peri-implant mucosal tissue conditions during supportive periodontal therapy (SPT). Clin Oral Implant Res 2000; 11: 521-9.

[21] Kamma JJ, Baehni PC. Five -year maintenance follow-up of early onset periodontitis patients. J Clin Periodontol 2003; 30: 562-72.

[22] Eguchi T, Koshy G, Umeda M, et al. Microbial changes after treatment with acute periodontal abscess after treatment detected by Pado test. Oral Dis 2008; 14:180-4.

[23] Cosgarea R, Bäumer A, Pretzl B, Zehaczek S, Kim TS. Comparison of two different microbiological test kits for detection of periodontal pathogens. Acta Odont Scand 2010; 68: 115-21.

[24] Dahlén G, Leonhardt ̊̊. A new checkerboard panel for testing bacterial markers in periodontal disease. Oral Microbiol Immunol 2006; 21: 6-11

[25] Socransky SS, Haffajee AD, Smith C et al. Use of checkerboard DNA-DNA hybridization to study complex microbiological ecosystems. Oral Microbiol Immunol 2004; 97: 1311-8.

[26] Marsh PD. Are dental diseases examples of ecological catastrophes? Microbiology 2003; 149: 279-94.

(C) Leonhardt et al.; Licensee Bentham Open.

This is an open access article licensed under the terms of the Creative Commons Attribution Non-Commercial License (http://creativecommons.org/licenses/by-nc/3.0/) which permits unrestricted, non-commercial use, distribution and reproduction in any medium, provided the work is properly cited. 